\title{
Association between Hypertension and the Risk of Parkinson's Disease: A Meta-Analysis of Analytical Studies
}

\author{
Jiahao Chen Caixia Zhang Yanjun Wu Dongfeng Zhang \\ Department of Epidemiology and Health Statistics, School of Public Health, Qingdao University, Qingdao, PR China
}

\section{Keywords}

Hypertension · Parkinson's disease · Meta-analysis

\section{Abstract}

Background: The results of analytical studies show that the association between hypertension and the risk of Parkinson's disease (PD) remains controversial. Method: We searched studies related to the association between hypertension and the risk of PD. We pooled the ORs and risk ratios (RRs) with 95\% confidence interval (Cl) with random effects model and conducted meta-regression to explore potential sources of heterogeneity. Publication bias was estimated by Egger's test and the funnel plot. Results: Twenty-six articles containing 27 studies were included, involving 9 cohort studies and 18 case-control studies. In cohort studies, compared with the non-hypertension participants, the pooled RR for the risk of PD was $1.70(95 \% \mathrm{Cl} 1.60-1.80)$ for the patients with hypertension. In case-control studies, compared with the non-hypertension participants, the pooled OR for the risk of PD was $0.85(95 \% \mathrm{Cl} 0.78-0.92)$ for the patients with hypertension. There were no publication bias in cohort studies and case-control studies. Conclusion: Based on population-based cohort studies, this meta-analysis indicated that hypertension might increase the risk of PD. In view of both hypertension and PD having an association with aging, case-control studies, especially the studies based on hospital records, were not suitable for similar studies.

(c) 2019 S. Karger AG, Basel

\section{Introduction}

Parkinson's disease (PD) is one of the most common neurodegenerative disorders, which is characterized by tremor, rigidity, bradykinesia, and postural instability [1]. Globally, the prevalence of PD is about $0.3 \%$ in individuals aged over 40 years [2, 3]. PD has complex etiology with combined effects of genetic and environmental factors [2, 4]. In some environmental exposure factors, alcohol intake [5, 6], drinking coffee [7], vitamin E intake [8], and use of nonsteroidal anti-inflammatory drugs [9] could reduce the PD risk; however, pesticide exposure [10-12] and milk intake [13] could increase the PD risk.
KARGER

() 2019 S. Karger AG, Basel

E-Mail karger@karger.com

www.karger.com/ned 
And studies founded that some diseases might have an effect on the risk of PD, such as asthma [14], diabetes [15, 16], and hypercholesterolemia [16], and so on.

Hypertension is one of the most common chronic diseases. According to World Health Organization, the global prevalence of hypertension was approximately $22 \%$ among adults in 2014, and the prevalence is expected to rise to $29.2 \%$ in 2025 without intervention [17]. Meanwhile, hypertension was strongly associated with the risk of stroke, cardiovascular disease, and kidney failure $[18,19]$.

Hypertension might cause hypertensive vasculopathy in the thalamus, brain stem, and basal ganglia [20], thus perhaps affecting the dopaminergic cells in the pars compacta and the connections between neurons in the substantia nigra and the putamen portion of the striatum. That might further cause the prevalence of PD. There were some studies about the association between hypertension and the risk of PD. Some studies [14, 16, 21, 22] founded hypertension could reduce the risk of PD. However, some studies [23-26] founded hypertension could increase the risk of PD. Given the different effects, we carried out this meta-analysis to assess the relationship between hypertension and the risk of PD.

\section{Methods}

Literature Search and Selection

A search of the literature up to 13 July 2018 was performed from the databases of PubMed, Web of Science, EMBASE, China National Knowledge Infrastructure, Wan fang, VIP (Database of Chinese Scientific and Technical Periodicals) and CBM (China biology medical literature database), using the following search terms: (hypertension or "high blood pressure") and (Parkinson's disease or Parkinson disease). The language was restricted to English and Chinese. Moreover, we also reviewed the references of the included studies to identify additional studies which were not captured by our database searches.

Two investigators (J.C. and Y.W.) reviewed all identified studies independently, and studies were included in this meta-analysis if they met the following criteria: (1) analytical studies (cohort studies and case-control studies); (2) the exposure of interest was hypertension; (3) the outcome of interest was PD; (4) multivariate-adjusted hazard ratio (HR) or risk ratio (RR) or odds ratio (OR) with $95 \%$ confidence interval (CI) were provided; (5) the most recent and complete article was chosen if a study had been published more than once.

\section{Data Extraction}

Two investigators (J.C. and C.Z.) extracted the following data from each study: (1) name of the first author; (2) year; (3) continent; (4) mean age of cases; (5) study type; (6) source of controls; (7) design of study; (8) number of cases; (9) sample size; (10) hypertension assessment; (11) OR, RR or HR with 95\% CI and (12) adjusted covariates.

\section{Statistical Analysis}

We weighted the study-specific log RRs and log ORs by the case number, to calculate pooled RRs and ORs with corresponding $95 \%$ $\mathrm{CI}$ of the association between hypertension and risk of PD. The $I^{2}$ was used to assess heterogeneity $\left(I^{2}\right.$ values of $0,25,50$, and $75 \%$ represent no, low, moderate and high heterogeneity respectively) [27]. The fixed-effect model was used as the pooling method if moderate or lower heterogeneity $\left(I^{2} \leq 50 \%\right)$ was found; otherwise $\left(I^{2}>50 \%\right)$, the random-effect model was adopted. Meta-regression with restricted maximum likelihood estimation was performed to assess the potentially important covariates that might exert substantial impact on between-study heterogeneity. After meta-regression, if we found a positive result, we further performed the permutation test to verify the accuracy of the results [28]. Subgroup analysis was performed based on the results of meta-regression. An influence analysis [29] was performed with one study removed at a time to assess whether the results could be markedly affected by a single study. Leave-one-out sensitivity analysis [30] was carried out to evaluate the key studies that have substantial impact on between-study heterogeneity. Publication bias was estimated using Egger regression asymmetry test [31] and the funnel plot.

All statistical analyses were performed with STATA version 15.0 (Stata Corporation, College Station, TX, USA). A 2-tailed $p \leq$ 0.05 was considered statistically significant.

\section{Results}

\section{Literature Search and Study Characteristics}

The search strategy identified 1,141 articles from PubMed, 212 articles from Web of Science, 2,800 articles from EMBASE, 64 articles from China National Knowledge Infrastructure, 407 articles from Wan fang, 83 articles from VIP and 260 articles from CBM. After duplicates being removed, 3,205 articles were excluded on screening of titles and/or abstract. After reading full text, 102 articles were excluded for the following reasons: duplicated reports from the same study population $(n=7)$; lacking OR, RR or HR and 95\% CI $(n=60)$; inverse exposure and outcome $(n=26)$; review $(n=9)$. Finally, 26 articles $[14-16,21-26,32-48]$ were included in this metaanalysis. The detailed literature search for article inclusion is shown in Figure 1.

Twenty-six articles containing 27 studies were included, involving 1,230,085 participants for population-based cohort studies and 32,121 participants for case-control studies. In population-based cohort studies, 2 studies were conducted in North America, 4 studies in Asia, and 3 studies in Europe. As for hypertension assessment, 6 studies were based on medical record, 2 studies on questionnaire, and one study on measurement of blood pressure. In casecontrol studies, 5 studies were conducted in North America, 8 studies in Asia, 4 studies in Europe and one study in 
Fig. 1. Selection of studies for inclusion in this meta-analysis. $\mathrm{RR}$, risk ratio; $\mathrm{HR}$, hazard ratio.
Records identified through searching PubMed $(n=1,141)$, Web of Science $(n=212)$, EMBASE $(n=2,800)$, CNKI

$(n=64)$, Wan Fang $(n=407)$, VIP $(n=83), \mathrm{CBM}(n=260)$

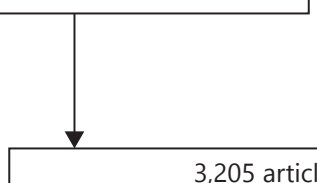

Additional records identified through reference list $(n=3)$ 3,077 articles excluded after review of title or abstract

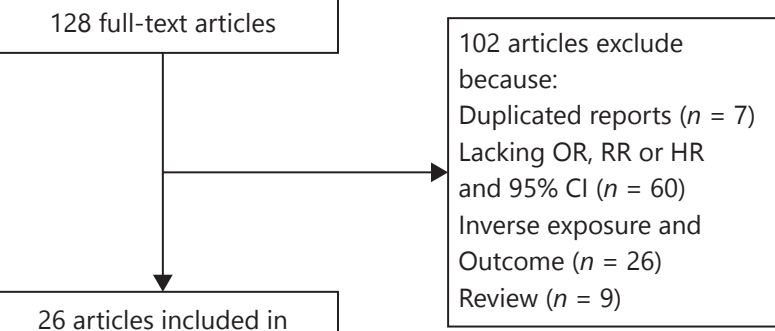

26 articles included in meta-analysis

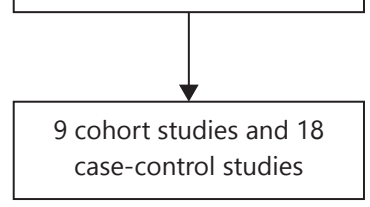

Oceania. As for the source of participants, 9 studies based on non-hospital, 6 studies based on hospital and 3 studies based on both hospital and non-hospital samples. As for hypertension assessment, 5 studies were based on medical record, 11 studies on questionnaire, and 2 studies on the measurement of blood pressure. The detailed characteristics of the included studies are shown in Table 1.

\section{Quantitative Synthesis}

In population-based cohort studies, the pooled RR of $\mathrm{PD}$ for the hypertension vs. non-hypertension was 1.70 (95\% CI 1.60-1.80; $\left.I^{2}=97.3 \%\right)$.

In case-control studies, the pooled OR of PD for the hypertension vs. non-hypertension was 0.85 (95\% CI $\left.0.78-0.92 ; I^{2}=87.8 \%\right)$. In the subgroup analysis by the source of participants, the pooled OR was 0.95 (95\% CI $0.88-1.03 ; I^{2}=89.7 \%$, $\left.p_{\text {heterogeneity }}<0.001\right)$ in studies based on non-hospital, 0.58 (95\% CI $0.48-0.70 ; I^{2}=34.7 \%$, $\left.p_{\text {heterogeneit }}=0.176\right)$ in studies based on hospital and 0.48
(95\% CI $0.27-0.84 ; I^{2}=68.9 \%$, $\left.p_{\text {heterogeneity }}=0.040\right)$ in studies based on non-hospital and hospital records (Table 2).

\section{Sources of Heterogeneity}

In population-based cohort studies, high heterogeneity among studies was found for hypertension with the risk of PD $\left(I^{2}=97.3 \%\right.$, $p_{\text {heterogeneity }}<0.001 ;$ Fig. 2$)$. To explore the sources of heterogeneity, meta-regression with the covariates of year, continent, sample size, case number, hypertension assessment, and the number of confounding factors were performed. The $p$ value was $0.268,0.178,0.932$, $0.331,0.240$, and 0.838 , respectively, which suggested that no covariates were the important sources of heterogeneity.

In case-control studies, high heterogeneity among studies was also found for hypertension with the risk of PD $\left(I^{2}\right.$ $=87.8 \%, p_{\text {heterogeneity }}<0.001 ;$ Fig. 3$)$. Meta-regression analysis was conducted with the covariates of year, continent, case number, sample size, hypertension assessment, the 


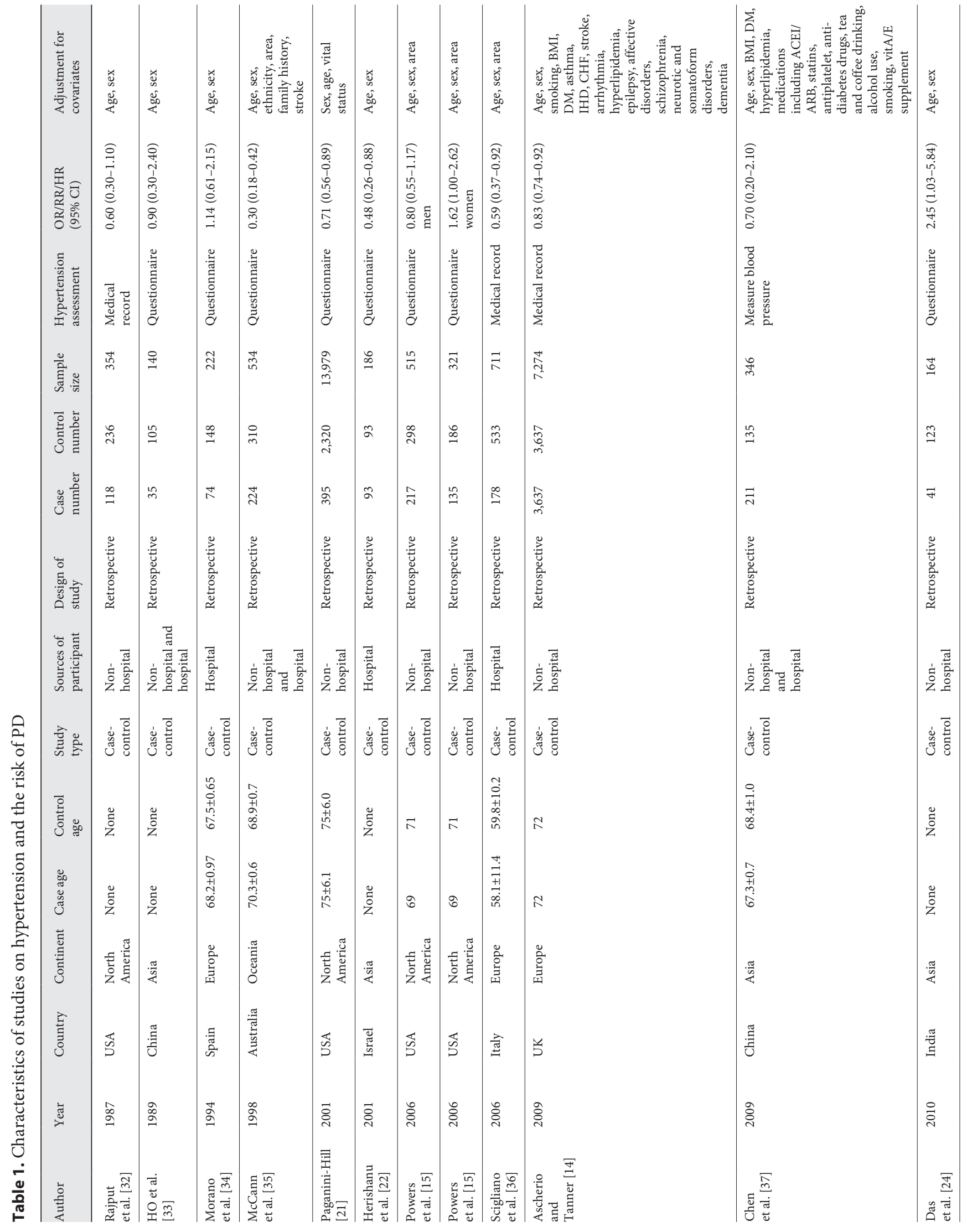




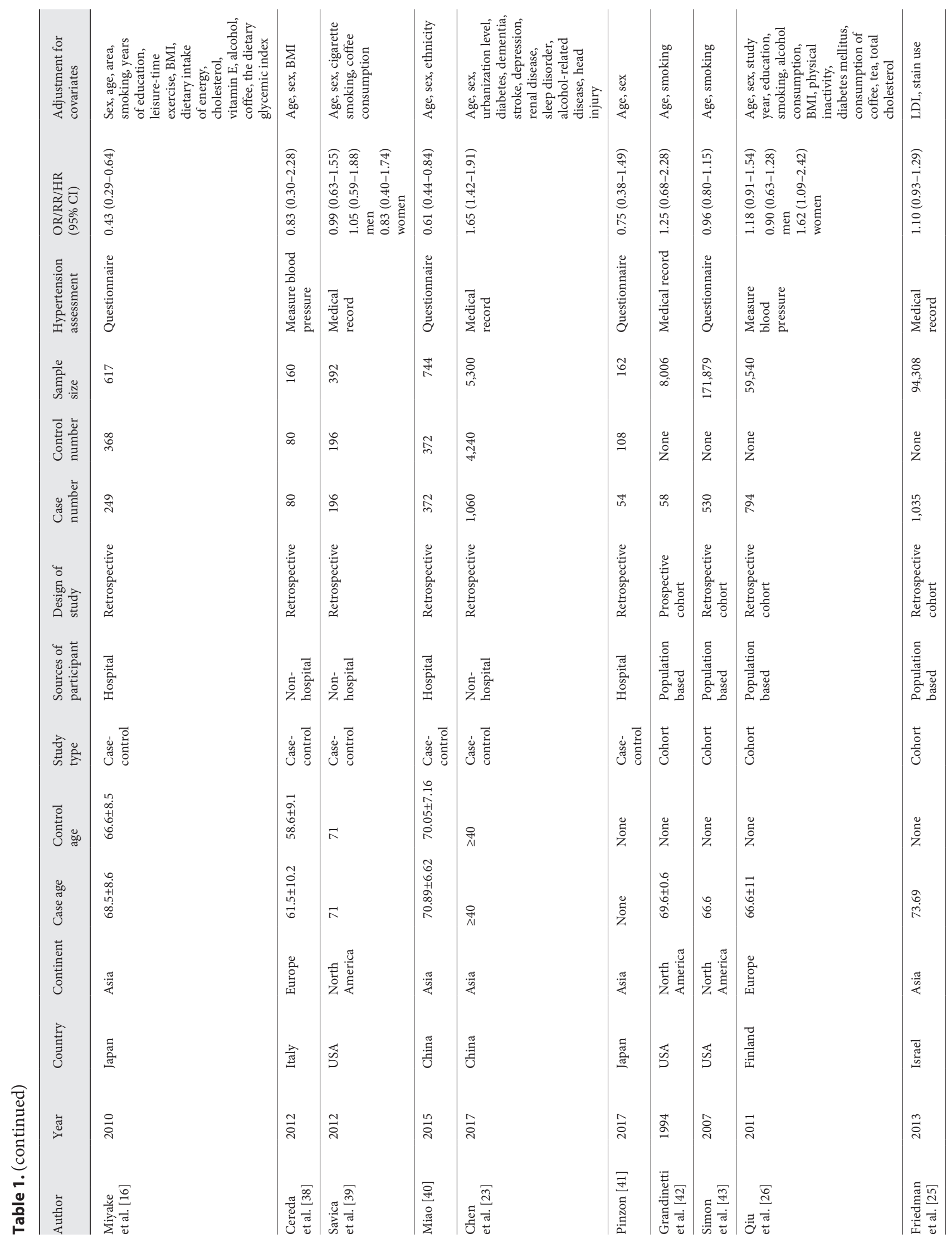




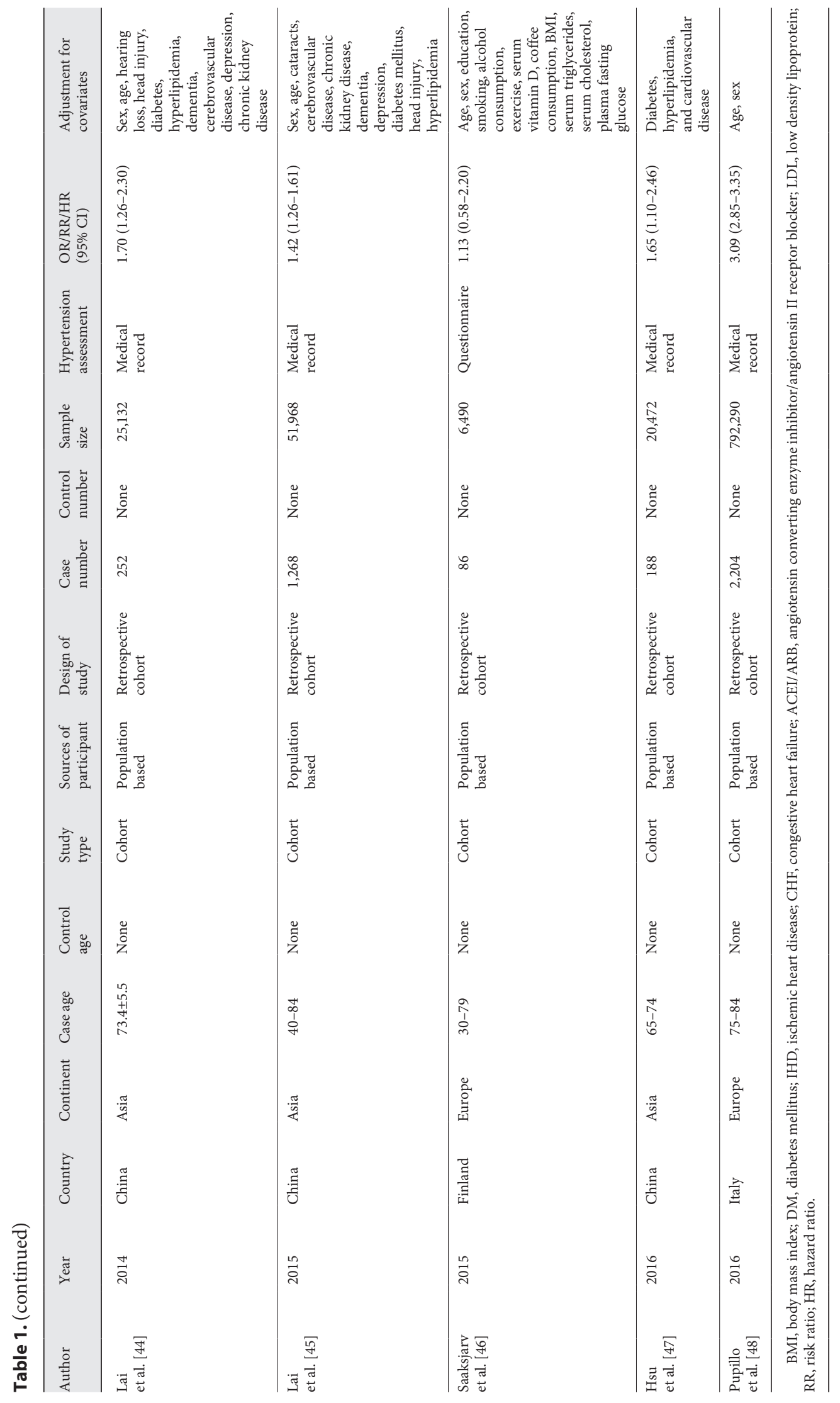


Table 2. Pooled ORs of the relationship between hypertension and the risk of PD

\begin{tabular}{lccrrr}
\hline Study characteristics & Number of studies & OR $(95 \% \mathrm{CI})$ & $p$ value & $I^{2}, \%$ & $p$ value \\
\hline All case-control studies & 18 & $0.85(0.78-0.92)$ & $<0.001$ & 87.8 \\
The source of participants & & & & $<0.001$ \\
$\quad$ Based on non-hospital & 9 & $0.95(0.88-1.03)$ & 0.204 & 89.7 \\
$\quad$ Based on non-hospital and hospital & 3 & $0.48(0.27-0.84)$ & 0.011 & 68.9 \\
$\quad$ Based on hospital & 6 & $0.58(0.48-0.70)$ & $<0.001$ & 34.7 \\
\hline
\end{tabular}

PD, Parkinson's disease.

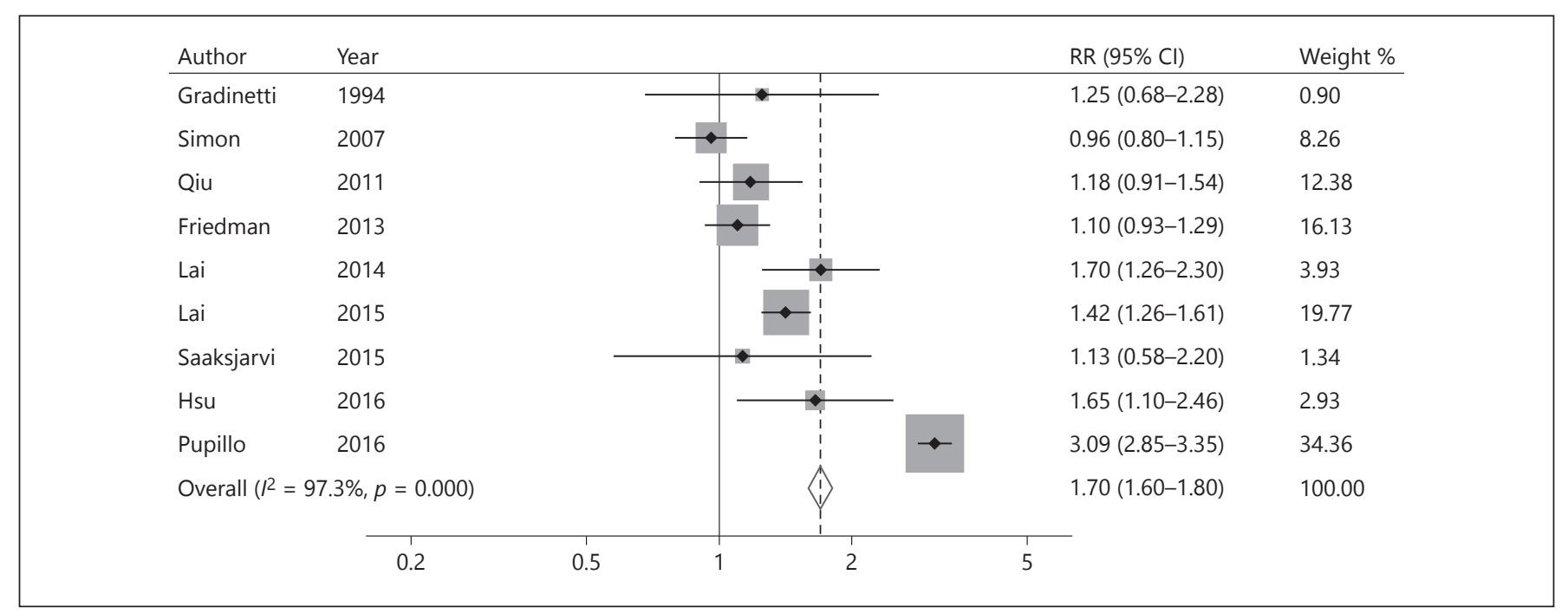

Fig. 2. Forest plot of the RRs with corresponding 95\% CIs of studies on hypertension and PD. The size of gray box is positively proportional to the weight assigned to each study, and horizontal lines represent the $95 \%$ CIs. $\mathrm{RR}$, risk ratio.

source of controls, and the number of confounding factors. The $p$ value of the covariates was $0.937,0.168,0.937,0.309$, $0.531,0.037$, and 0.479 , respectively. We further performed permutation test, and the $p$ value for the source of controls was 0.044 , which suggested that the source of controls was the important sources of heterogeneity.

\section{Influence Analysis}

In population-based cohort studies, influence analysis showed that 4 studies $[25,43,45,48]$ had an excessive influence on the pooled RR (Fig. 4). After excluding the excessive influential studies, the pooled results did not change obviously (RR 1.32; 95\% CI 1.11-1.58; $I^{2}=17.2 \%$ ).

In case-control studies, influence analysis showed that one study [23] had an excessive influence on the pooled OR(Fig. 5). After excluding the excessive influential study, the pooled results was $0.76\left(95 \% \mathrm{CI} 0.69-0.83 ; I^{2}=70.7 \%\right)$.

\section{Sensitivity Analyses}

By using the leave-one-out sensitivity analysis, 2 articles contributed to high between-study heterogeneity in population-based cohort studies. After further excluding these 2 articles $[43,48]$, low heterogeneity $\left(I^{2}=\right.$ $47.2 \%)$ was found and the pooled RR was 1.29 (95\% CI $1.17-1.41)$.

The results from case-control studies showed that 3 articles contributed to high between-study heterogeneity. After further excluding these 3 articles [16, 23, 35], the pooled OR was $0.81\left(95 \%\right.$ CI $\left.0.73-0.88 ; I^{2}=46.5 \%\right)$.

\section{Publication Bias}

Egger test showed no evidence of significant publication bias for the analysis between hypertension and the risk of $\mathrm{PD}$ ( $p=0.121$ for population-based cohort studies, $p=0.313$ for case-control studies; Figs. 6, 7). 


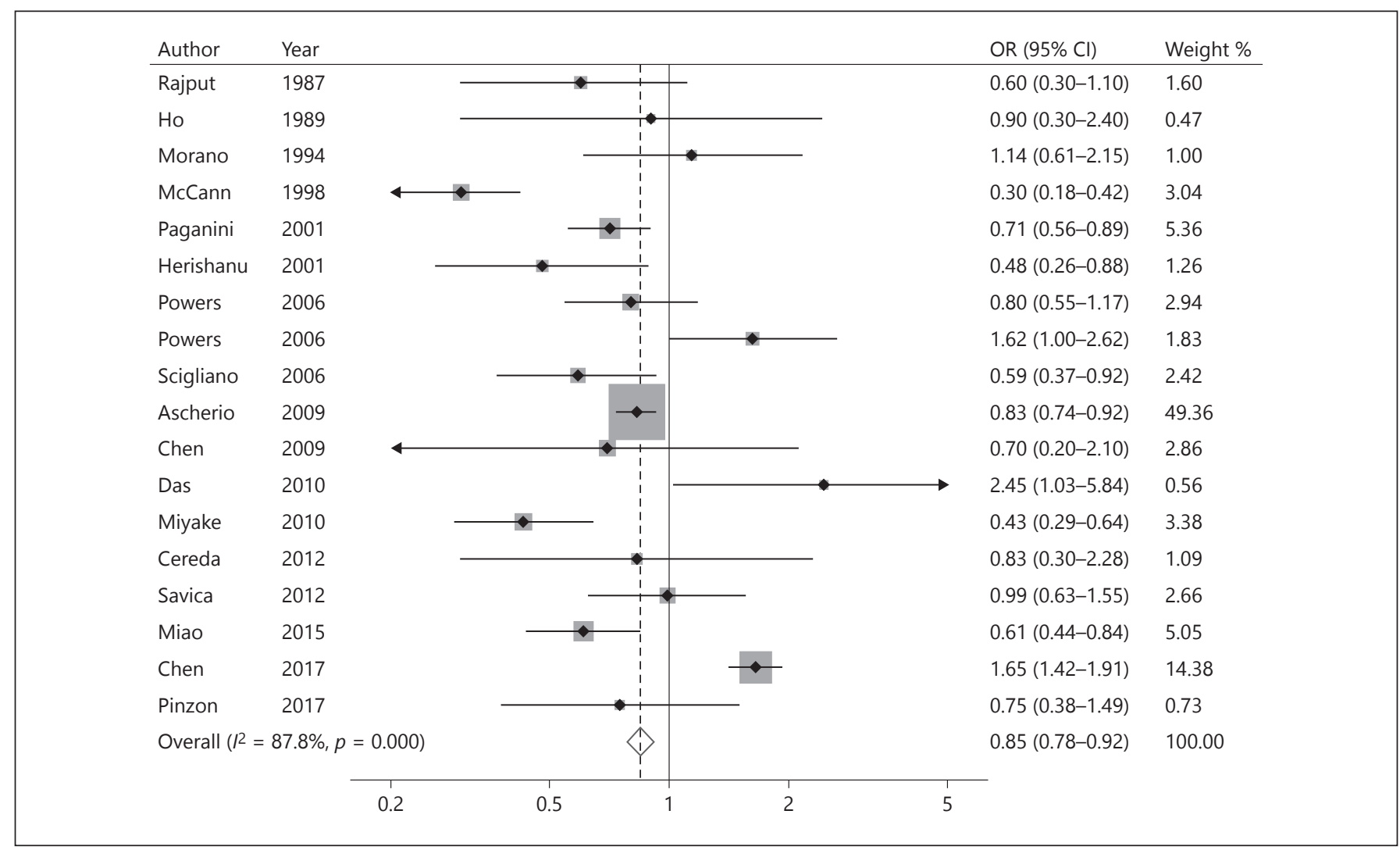

Fig. 3. Forest plot of the OR with corresponding 95\% CIs of studies on hypertension and PD. The size of gray box is positively proportional to the weight assigned to each study, and horizontal lines represent the $95 \%$ CIs.

Fig. 4. Influence analysis of individual study on the pooled RR for studies on hypertension and PD.

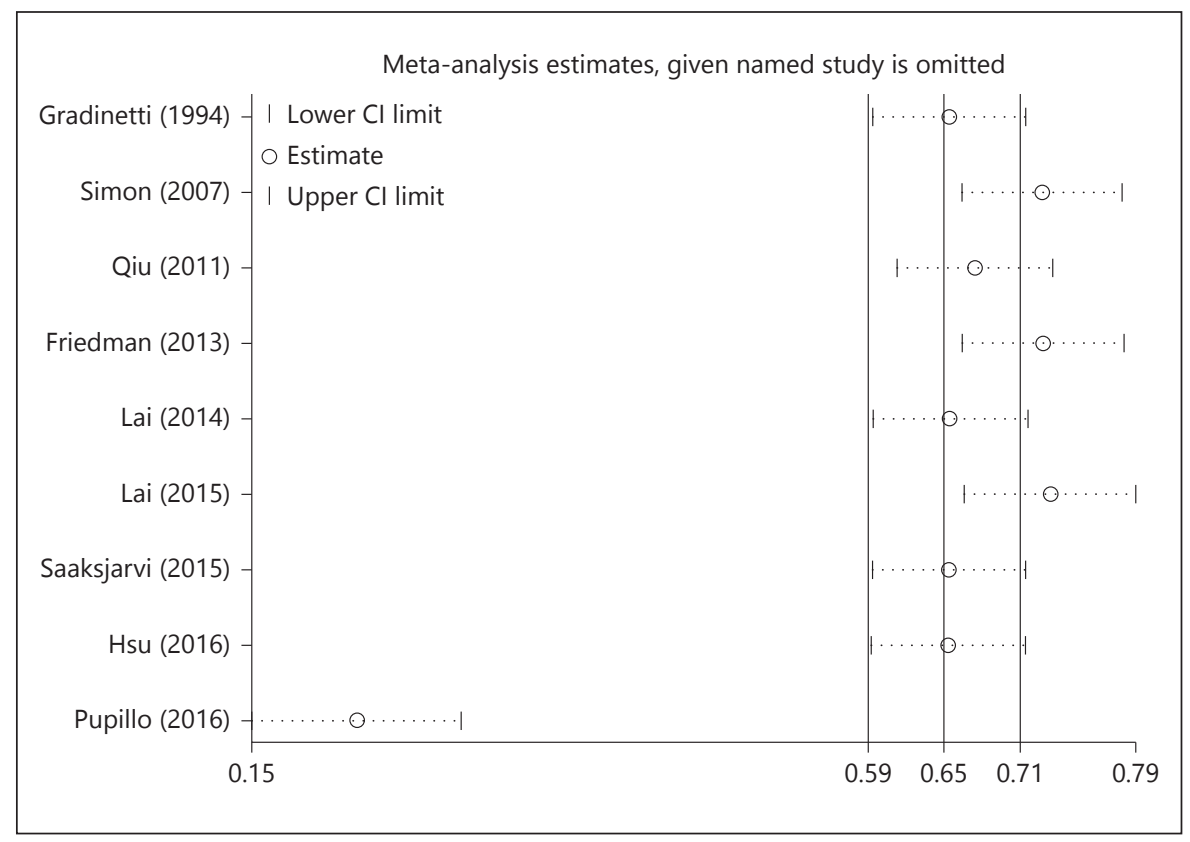


Fig. 5. Influence analysis of individual study on the pooled OR for studies on hypertension and PD.
Meta-analysis estimates, given named study is omitted

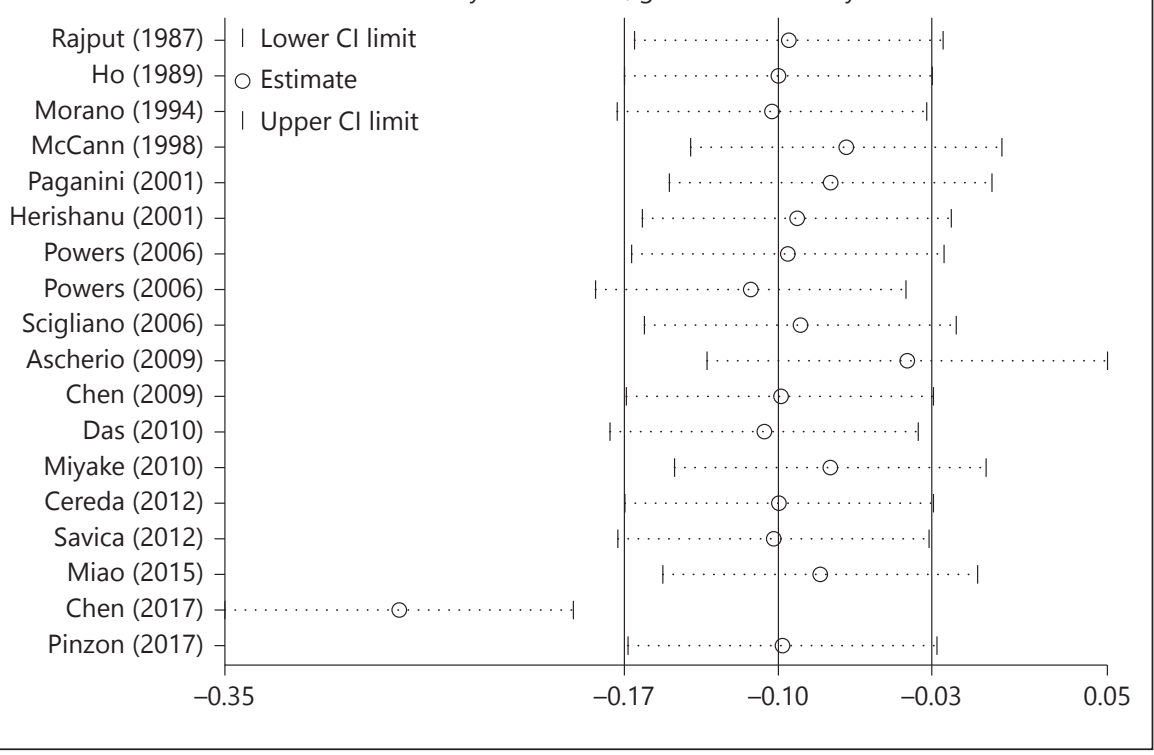

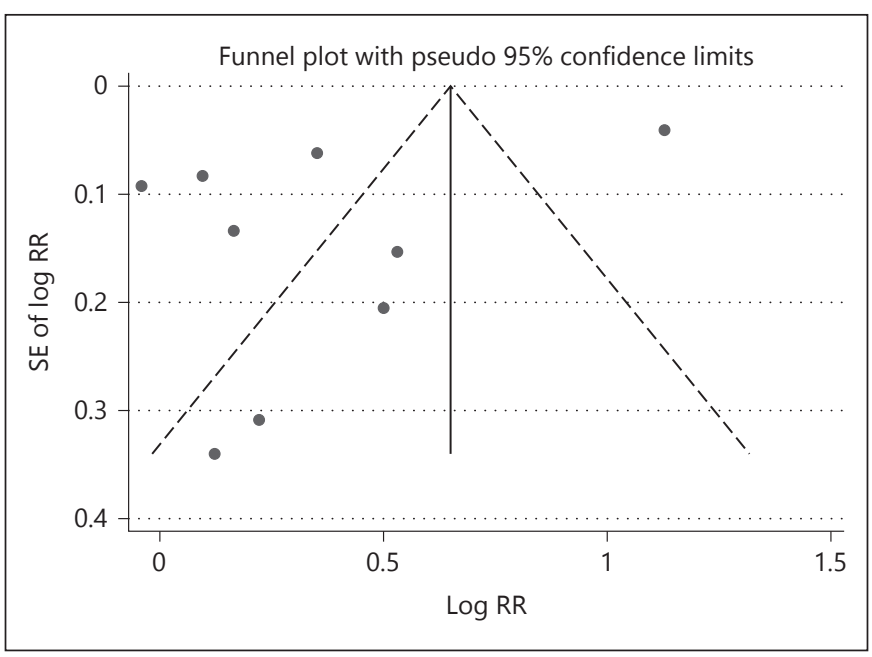

Fig. 6. The funnel plot of hypertension and the risk of PD of cohort studies. Each dot represents a different study.

\section{Discussion}

This meta-analysis provides a comprehensive evaluation of the association between hypertension and the risk of PD. The results from population-based cohort studies indicated that hypertension might increase the risk of PD. But the results from case-control studies indicated that hypertension might decrease the risk of PD. There was inconsistency between population-based cohort studies and case-control studies.

Association between Hypertension and the Risk of PD

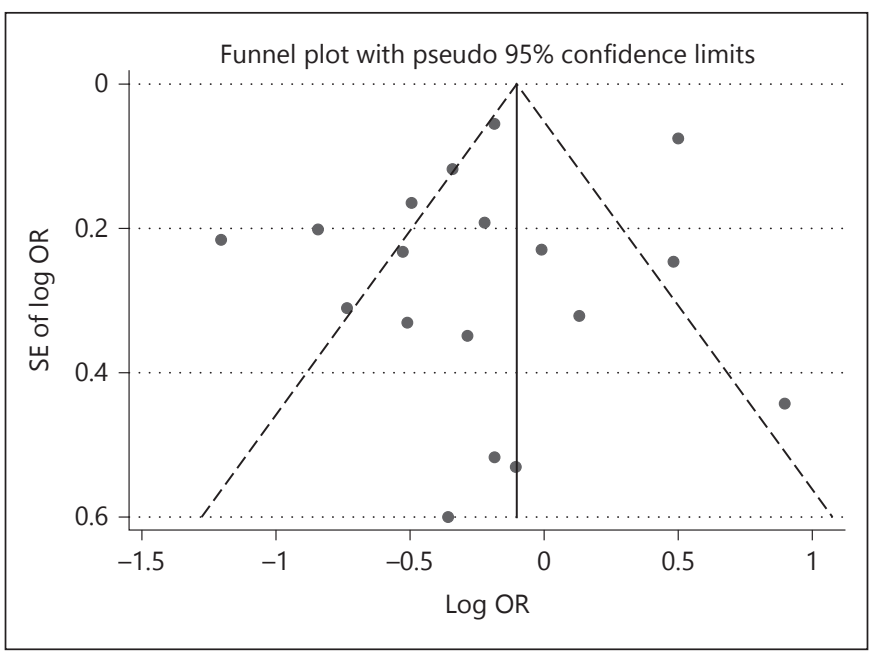

Fig. 7. The funnel plot of hypertension and the risk of PD of casecontrol studies. Each dot represents a different study.

In population-based cohort studies, the pooled RR indicated that hypertension might increase the risk of PD. And the results from leave-one-out sensitivity analysis also indicated that hypertension might increase the risk of PD. And these results were the same as those of the previous study, which included 6 cohort articles conducted by Hou et al. [49]. Meanwhile, compared with Hou et al. [49], our meta-analysis contained influence analysis. In influence analysis, 4 studies had an excessive influence on the pooled RR. After removing 
these 4 articles, the pooled results were still significant, indicating the pooled RR was not significantly affected by these 4 studies and the positive results were stable.

In case-control studies, the pooled OR indicated that hypertension could decrease the risk of $\mathrm{PD}$, and the results from leave-one-out sensitivity analysis and influence analysis also supported this association. However, in subgroup analysis, the result from studies based on nonhospital records indicated there were no association between hypertension and the risk of PD.

We found the results from case-control studies were opposite to the results from population-based cohort studies. Here are some possible reasons for the inconsistency: First, PD is a typical senile disease with an average onset age of about 60 years old. According to the World Health Organization in 2014, the global prevalence of hypertension was about $50 \%$ among people aged more than 60 years old, and about $22 \%$ among general population. The above data indicated both hypertension and PD had close association with aging. So in the age-matched control group, it was more likely to select the elderly with hypertension. Especially in the case-control studies based on hospital records, the proportion of hypertension in control group was higher; for example, in the study conducted by Pinzon et al. [41], the proportion of hypertension in control group was $69.44 \%$. There were more hypertension patients in the control group; thus, we were more likely to get the protective results. Similarly, case-control studies were not suitable for the studies about analogous diseases and PD. Second, both hypertension and PD were diseases with a long course; it was difficult to determine the sequence of onset of PD and hypertension in casecontrol studies. Moreover, there were recall bias in case-control studies [50], especially in the studies based on questionnaire in this meta-analysis. Thus, the evaluation of the relationship between hypertension and PD was inevitably affected.

Between-study heterogeneity occurs frequently in meta-analysis [27]. In this meta-analysis, high heterogeneity were found $\left(I^{2}=97.3 \%\right.$ for cohort studies; $I^{2}=87.8 \%$ for case-control studies). However, the between-study heterogeneity in population-based cohort studies was not successfully explained. But in case-control studies, the results from meta-regression and permutation test suggested that the source of controls was the important sources of heterogeneity. The results from subgroup analysis also revealed the sources of heterogeneity. In different sources of participants, the controls from hospital tended to have increased frequency of hypertension [37], so the pooled OR based on hospital records was lower.

As a meta-analysis of relevant published studies, our study has several strengths. First, though there were one prospective cohort study and 8 retrospective cohort studies, all of these 9 were prospective studies from exposure to outcome, so the significant positive result was more persuasive. Second, these 9 cohort studies were general population-based studies, so the results can be better extended to the general population. Third, the sample size in this meta-analysis was large, enabled a much greater possibility of reaching reasonable conclusions. Fourth, we extracted RRs, ORs, or HRs that reflected the greatest degree of control for potential confounders, increasing the credibility of the conclusions.

Nevertheless, our study also has limitations. First, the confounder of usage of antihypertensive drugs could not be adjusted, which is a very important factor affecting the association between hypertension and the risk of PD. Some studies $[14,51]$ found the use of antihypertensive drugs could reduce the risk of PD. Second, confounders adjusted in studies were different, which could affect the association between hypertension and the risk of PD. Third, the pooled results of populationbased cohort studies and case-control studies were contrary, so we could not calculate the total pooled results of analytical studies. Finally, high between-study heterogeneity in cohort study was found, but it was not completely explained by meta-regression and subgroup analysis.

Based on population-based cohort studies, this metaanalysis indicated hypertension might increase the risk of PD. In view of both hypertension and PD had association with aging, case-control studies especially the studies based on hospital records were not suitable for similar studies.

\section{Ethics Statement}

The authors have no ethical conflicts to disclose.

\section{Disclosure Statement}

The authors have no conflicts of interest to declare.

\section{Funding Sources}

No funding was received for this study. 


\section{References}

1 Zheng KS, Dorfman BJ, Christos PJ, Khadem NR, Henchcliffe C, Piboolnurak P, Nirenberg MJ: Clinical characteristics of exacerbations in Parkinson disease. Neurologist 2012;18: 120-124.

2 de Lau LM, Breteler MM: Epidemiology of Parkinson's disease. Lancet Neurol 2006;5: 525-535.

3 Pringsheim T, Jette N, Frolkis A, Steeves TD: The prevalence of Parkinson's disease: a systematic review and meta-analysis. Mov Disord 2014;29:1583-1590.

4 Wirdefeldt K, Adami HO, Cole P, Trichopoulos D, Mandel J: Epidemiology and etiology of Parkinson's disease: a review of the evidence. Eur J Epidemiol 2011;26(suppl 1):S1-S58.

5 Liu R, Guo X, Park Y, Wang J, Huang X, Hollenbeck A, Blair A, Chen H: Alcohol consumption, types of alcohol, and Parkinson's disease. PLoS One 2013;8:e66452.

6 Zhang D, Jiang H, Xie J: Alcohol intake and risk of Parkinson's disease: a meta-analysis of observational studies. Mov Disord 2014;29: 819-822.

7 Hernan MA, Takkouche B, Caamano-Isorna F, Gestal-Otero JJ: A meta-analysis of coffee drinking, cigarette smoking, and the risk of Parkinson's disease. Ann Neurol 2002;52: 276-284.

8 Etminan M, Gill SS, Samii A: Intake of vitamin $\mathrm{E}$, vitamin $\mathrm{C}$, and carotenoids and the risk of Parkinson's disease: a meta-analysis. Lancet Neurol 2005;4:362-365.

9 Gagne JJ, Power MC: Anti-inflammatory drugs and risk of Parkinson disease: a metaanalysis. Neurology 2010;74:995-1002.

10 Li AA, Mink PJ, McIntosh LJ, Teta MJ, Finley B: Evaluation of epidemiologic and animal data associating pesticides with Parkinson's disease. J Occup Environ Med 2005;47:10591087.

11 Priyadarshi A, Khuder SA, Schaub EA, Shrivastava S: A meta-analysis of Parkinson's disease and exposure to pesticides. Neurotoxicology 2000;21:435-440.

12 Priyadarshi A, Khuder SA, Schaub EA, Priyadarshi SS: Environmental risk factors and Parkinson's disease: a metaanalysis. Environ Res 2001;86:122-127.

13 Jiang W, Ju C, Jiang H, Zhang D: Dairy foods intake and risk of Parkinson's disease: a doseresponse meta-analysis of prospective cohort studies. Eur J Epidemiol 2014;29:613-619.

14 Ascherio A, Tanner CM: Use of antihypertensives and the risk of Parkinson disease. Neurology 2009;72:578-579.

15 Powers KM, Smith-Weller T, Franklin GA, Longstreth WT Jr, Swanson PD, Checkoway $\mathrm{H}$ : Diabetes, smoking, and other medical conditions in relation to Parkinson's disease risk. Parkinsonism Relat Disord 2006;12:185-189.

16 Miyake Y, Tanaka K, Fukushima W, Sasaki S, Kiyohara C, Tsuboi Y, Yamada T, Oeda T, Miki T, Kawamura N, Sakae N, Fukuyama H, Hirota Y, Nagai M; Fukuoka Kinki Parkin- son's Disease Study Group: Case-control study of risk of Parkinson's disease in relation to hypertension, hypercholesterolemia, and diabetes in Japan. J Neurol Sci 2010;293:8286.

17 Kearney PM, Whelton M, Reynolds K, Muntner P, Whelton PK, He J: Global burden of hypertension: analysis of worldwide data. Lancet 2005;365:217-223.

18 Faraco G, Iadecola C: Hypertension: a harbinger of stroke and dementia. Hypertension 2013;62:810-817.

19 Chobanian AV, Bakris GL, Black HR, Cushman WC, Green LA, Izzo JL Jr, Jones DW, Materson BJ, Oparil S, Wright JT Jr, Roccella EJ; Joint National Committee on Prevention, Detection, Evaluation, and Treatment of High Blood Pressure. National Heart, Lung, and Blood Institute; National High Blood Pressure Education Program Coordinating Committee: Seventh report of the joint National committee on prevention, detection, evaluation, and treatment of high blood pressure. Hypertension 2003;42:12061252.

20 Greenberg SM, Vernooij MW, Cordonnier C, Viswanathan A, Al-Shahi Salman R, Warach S, Launer LJ, Van Buchem MA, Breteler MM: Cerebral microbleeds: a guide to detection and interpretation. Lancet Neurol 2009;8: 165-174.

21 Paganini-Hill A: Risk factors for Parkinson's disease: the leisure world cohort study. Neuroepidemiology 2001;20:118-124.

22 Herishanu YO, Medvedovski M, Goldsmith JR, Kordysh E: A case-control study of Parkinson's disease in urban population of southern Israel. Can J Neurol Sci 2001;28: 144-147.

23 Chen CY, Hung HJ, Chang KH, Hsu CY, Muo $\mathrm{CH}$, Tsai CH, Wu TN: Long-term exposure to air pollution and the incidence of Parkinson's disease: a nested case-control study. PLoS One 2017; 12:e0182834.

24 Das SK, Misra AK, Ray BK, Hazra A, Ghosal MK, Chaudhuri A, Roy T, Banerjee TK, Raut DK: Epidemiology of Parkinson disease in the city of Kolkata, India: a community-based study. Neurology 2010;75:1362-1369.

25 Friedman B, Lahad A, Dresner Y, Vinker S: Long-term statin use and the risk of Parkinson's disease. Am J Manag Care 2013;19:626632.

26 Qiu C, Hu G, Kivipelto M, Laatikainen T, Antikainen R, Fratiglioni L, Jousilahti P, Tuomilehto J: Association of blood pressure and hypertension with the risk of Parkinson disease: the National FINRISK study. Hypertension 2011;57:1094-1100.

27 Higgins JP, Thompson SG, Deeks JJ, Altman DG: Measuring inconsistency in meta-analyses. BMJ 2003;327:557-560.

28 Higgins JP, Thompson SG: Controlling the risk of spurious findings from meta-regression. Stat Med 2004;23:1663-1682.
29 Tobias A: Assessing the influence of a single study in the meta-analysis estimate. Stata Tech Bull 1999;8:7526-7529.

30 Patsopoulos NA, Evangelou E, Ioannidis JP: Sensitivity of between-study heterogeneity in meta-analysis: proposed metrics and empirical evaluation. Int J Epidemiol 2008;37:11481157.

31 Egger M, Davey Smith G, Schneider M, Minder C: Bias in meta-analysis detected by a simple, graphical test. BMJ 1997;315:629-634.

32 Rajput AH, Offord KP, Beard CM, Kurland LT: A case-control study of smoking habits, dementia, and other illnesses in idiopathic Parkinson's disease. Neurology 1987;37:226232

33 Ho SC, Woo J, Lee CM: Epidemiologic study of Parkinson's disease in Hong Kong. Neurology 1989;39:1314-1318.

34 Morano A, Jimenez-Jimenez FJ, Molina JA, Antolin MA: Risk-factors for Parkinson's disease: case-control study in the province of caceres, Spain. Acta Neurol Scand 1994;89:164170 .

35 McCann SJ, LeCouteur DG, Green AC, Brayne C, Johnson AG, Chan D, McManus ME, Pond SM: The epidemiology of Parkinson's disease in an Australian population. Neuroepidemiology 1998;17:310-317.

36 Scigliano G, Musicco M, Soliveri P, Piccolo I, Ronchetti G, Girotti F: Reduced risk factors for vascular disorders in Parkinson disease patients: a case-control study. Stroke 2006;37: 1184-1188.

37 Chen CM, Liu JL, Wu YR, Chen YC, Cheng HS, Cheng ML, Chiu DT: Increased oxidative damage in peripheral blood correlates with severity of Parkinson's disease. Neurobiol Dis 2009;33:429-435.

38 Cereda E, Cassani E, Barichella M, Spadafranca A, Caccialanza R, Bertoli S, Battezzati A, Pezzoli G: Low cardiometabolic risk in Parkinson's disease is independent of nutritional status, body composition and fat distribution. Clin Nutr 2012;31:699-704.

39 Savica R, Grossardt BR, Ahlskog JE, Rocca WA: Metabolic markers or conditions preceding Parkinson's disease: a case-control study. Mov Disord 2012;27:974-979.

40 Miao G: A Case-Control Study on the Risk of Hypertension, Hyperuricemia, Lifestyle and Parkinson's Disease. Suzhou, Soochow University, 2015, pp 1-36.

41 Pinzon R: Is hypertension and certain anti hypertensive agents increase the risk of Parkinson disease? J Hypertens 2017;35.

42 Grandinetti A, Morens DM, Reed D, MacEachern D: Prospective study of cigarette smoking and the risk of developing idiopathic Parkinson's disease. Am J Epidemiol 1994; 139:1129-1138.

43 Simon KC, Chen H, Schwarzschild M, Ascherio A: Hypertension, hypercholesterolemia, diabetes, and risk of Parkinson disease. Neurology 2007;69:1688-1695. 
44 Lai SW, Liao KF, Lin CL, Lin CC, Sung FC: Hearing loss may be a non-motor feature of Parkinson's disease in older people in Taiwan. Eur J Neurol 2014;21:752757.

45 Lai SW, Lin CL, Liao KF, Chang-Ou KC: Increased risk of Parkinson's disease in cataract patients: a population-based cohort study. Parkinsonism Relat Disord 2015;21: 68-71.

46 Saaksjarvi K, Knekt P, Mannisto S, Lyytinen J, Heliovaara M: Prospective study on the components of metabolic syndrome and the incidence of Parkinson's disease. Parkinsonism Relat Disord 2015;21:11481155.

47 Hsu YC, Chang CW, Lee HL, Chuang CC, Chiu HC, Li WY, Horng JT, Fu E: Association between history of dental amalgam fillings and risk of Parkinson's disease: a population-based retrospective cohort study in Taiwan. PLoS One 2016;11: e0166552.

48 Pupillo E, Cricelli C, Mazzoleni F, Cricelli I, Pasqua A, Pecchioli S, Lapi F, Beghi E: Epidemiology of Parkinson's disease: a population- based study in primary care in Italy. Neuroepidemiology 2016;47:38-45.

49 Hou L, Li Q, Jiang L, Qiu H, Geng C, Hong JS, $\mathrm{Li} \mathrm{H}$, Wang Q: Hypertension and diagnosis of Parkinson's disease: a meta-analysis of cohort studies. Front Neurol 2018;9:162.

50 Lash TL, Rothman K, Greenland: Modern Epidemiology 3rd 2008. Lippincott, Williams, and Wilkins.

51 Lee YC, Lin $\mathrm{CH}, \mathrm{Wu} \mathrm{RM}$, Lin JW, Chang $\mathrm{CH}$, Lai MS: Antihypertensive agents and risk of Parkinson's disease: a nationwide cohort study. PLoS One 2014;9:e98961. 